\title{
O corpo performático nas redes sociais: narrativas audiovisuais no reels do Instagram
}

\author{
The performative body on social media: audiovisual narratives on \\ Instagram reels
}

El cuerpo performativo en redes sociales: narrativas audiovisuales en reels de Instagram

\author{
Renata Pitombo CIDREIRA ${ }^{1}$ \\ Naiara Moura PINTO²
}

\section{Resumo}

Este trabalho discute a concepção de performance pela copresença através das redes sociais, a partir de uma reflexão sobre o corpo performático observando a funcionalidade reels do Instagram enquanto meio para narrativas audiovisuais que se consolidou durante a pandemia de Covid-19 entre 2020 e 2021. Realizamos uma análise de conteúdo examinando os vídeos publicados nos perfis de quatro influenciadoras digitais, relacionando-os com as trajetórias das mesmas. A reflexão deste trabalho enfatiza a centralidade do corpo nas práticas comunicacionais no contexto pandêmico e pós-pandêmico utilizando-se das funcionalidades das redes sociais como meios de partilha de significados e narrativas individuais.

Palavras-chave: Corpo performático; Narrativa audiovisual; Rede Social.

\footnotetext{
Abstract

This article discusses the concept of performance through co-presence through social networks, from a reflection on the performative body, observing the reels functionality of Instagram as a media for audiovisual narratives consolidated amid the Covid-19 pandemic between 2020 and 2021. We have fulfilled content analysis and examined

${ }^{1}$ Doutora em Comunicação e Cultura Contemporâneas pela Universidade Federal da Bahia (UFBA) Professora de Jornalismo e Publicidade do Centro de Artes, Humanidades e Letras da Universidade Federal do Recôncavo da Bahia (UFRB) - E-mail: pitomboc@yahoo.com.br - ORCID: 0000-00021281-623X.

${ }^{2}$ Mestra em Comunicação pela Universidade Federal do Recôncavo da Bahia (UFRB) - Doutoranda em Cultura e Sociedade pelo Programa Multidisciplinar de Pós-Graduação em Cultura e Sociedade (PósCultura) na Universidade Federal da Bahia (UFBA) - E-mail: naiara.moura@ufba.br - ORCID: oooo0002-5757-510X.
} 
the videos published in the profiles of four digital influencers, relating them to their trajectories. The reflection of this work emphasizes the centrality of the body in communicational practices in the pandemic and post-pandemic context, using the functionalities of social networks as a media of sharing meanings and individual narratives.

Keywords: Performative body; Audiovisual narrative; Social Media.

\section{Resumen}

En este trabajo se analiza la concepción de la performance a través de la copresencia a través de las redes sociales, a partir de una reflexión sobre el cuerpo performativo, observando la funcionalidad reels de Instagram como medio de narrativas audiovisuales que se consolidó en medio de la pandemia Covid-19 entre 2020 y 2021. Realizando un análisis de contenido, examinamos los videos publicados en los perfiles de cuatro influencers digitales, relacionándolos con sus trayectorias. La reflexión de este trabajo enfatiza la centralidad del cuerpo en las prácticas comunicacionales en el contexto pandémico y pospandémico, utilizando las funcionalidades de las redes sociales como medio para compartir significados y narrativas individuales.

Palabras clave: Cuerpo performativo; Narrativa audiovisual; Red social.

\section{Introdução}

As práticas de sociabilidade pelo universo on-line ganharam uma maior relevância para a manutenção de atividades cotidianas, como estudar e trabalhar, bem como de atividades sociais, como acompanhar concertos musicais ou dialogar em grupos, desde março de 2020, com a chegada da pandemia de Covid-19 e a recomendação do distanciamento social. As redes sociais digitais, portanto, tornaramse um espaço ainda mais relevante na vida das pessoas, pois, através delas, era e é possível acompanhar e vivenciar, de alguma forma, alguns momentos do dia a dia de pessoas conhecidas ou de celebridades com as quais nos conectamos.

Sites de redes sociais permitem a construção de uma persona através de páginas pessoais que possibilitam interação entre os atores sociais que ali estão inseridos através de comentários, curtidas e compartilhamentos, bem como fomentando a exposição pública destes (RECUERO, 2014). Dentre as ferramentas das redes sociais que emergiram e se destacaram em 2020, a produção e compartilhamento de vídeos curtos tornou-se massiva em plataformas diferentes como Kwai, TikTok e Instagram, na função reels, lançada em agosto de 2020. O recurso reels fora testado inicialmente 
no Brasil, França e Alemanha3 e permite que os usuários do Instagram produzam vídeos a partir de áudios, efeitos e outras ferramentas de criação que podem ser apropriadas a partir do que outros usuários publicaram. A navegabilidade e a proposta da função se assemelham com as dos aplicativos Kwai e TikTok.

Recuero (2014) orienta que, ao estudarmos redes sociais, analisamos uma metáfora de elementos dinâmicos dos grupos sociais que possibilitam expressão e socialização através da comunicação mediada pelo computador. As mudanças provocadas pelo tecido das redes sociais mundialmente são descritas por Sibilia (2008) como práticas de difícil qualificação, "rituais bastante variados, que brotam em todos os cantos do mundo e não cessam de ganhar novos adeptos dia após dia” (SIBILIA, 2008, p.12). Neste trabalho, argumentamos que, através da função reels do Instagram, há uma dimensão performativa dos corpos que aparecem nos vídeos publicados, gerando e disseminando narrativas audiovisuais sobre aqueles que os produzem.

Sendo toda subjetividade encarnada em um corpo (embodied) e também embebida em uma cultura intersubjetiva (embedded) (SIBILIA,2008), ao tentarmos compreender as práticas de expressão e comunicação na internet, investigaremos a dimensão performativa a partir de algumas aproximações teóricas por se tratar de um objeto de pesquisa emergente. Relacionamos a discussão sobre performance e performatividade na vida cotidiana. Dentre os autores que discutem e delineiam noções de performance, destacamos Renato Cohen (2002) e Paul Zumthor (2016), aderindo às proposições de Erving Goffman (1985) pela concepção de representação, além do pioneiro nos estudos da área, Richard Schechner (2013).

Como se trata de uma maneira fundamental de compreensão do mundo, a narrativa é entendida como uma cadeia de eventos que são conectados por causa e efeito ocorrendo no espaço e tempo (BORDWELL; THOMPSON, 2013), especificamente dentro da narrativa cinematográfica. Situamos a reflexão sobre a narrativa a partir do que Martino (2016) delineia aproximando-a de uma dimensão estética da comunicação, relacionando-o ao olhar de França (2006) sobre os sujeitos em comunicação. Sibilia (2008) contribui para a discussão tratando da infinidade de "eus" aos quais estamos submetidos ao explorarmos as vidas nas redes sociais, dos quais destacamos o eu narrador. Assim, pretendemos observar como os vídeos

3 Fonte: <https://about.instagram.com/pt-br/blog/announcements/introducing-instagram-reelsannouncement>. Acesso em: 29 out. 2021 Ver APRESENTAMOS (2020). 
publicados no reels são apropriados como um meio para narrativas audiovisuais capazes de vincular produtores de conteúdo e sua audiência.

Aderimos à análise de conteúdo como conjunto de técnicas para análises das comunicações e culturas on-line, conforme descrita por Bardin (2002). Na imersão na rede social Instagram no estágio de pré-análise, delineou-se o corpus de observação deste trabalho pela definição das influenciadoras digitais e produtoras de conteúdo Maíra Azevedo, Dirce Ferreira, Lorrane Silva e Alexandra Gurgel, cujas trajetórias revelaram-se cruciais na conformação das suas narrativas audiovisuais no reels, conforme analisamos a seguir. A abordagem qualitativa para os dados levantados é pertinente, pois funciona em corpus de pesquisa reduzido e considera os problemas conforme o nível de pertinência (BARDIN, 2002). As inferências, portanto, são fundadas na presença do índice (tema, palavra, personagem etc.), e não na frequência da sua aparição em cada comunicação individual.

\section{A copresença e o corpo performático}

Perspectivas diversas nos auxiliam a delinear uma concepção ampla de performance que se situe no corpus de análise deste trabalho; por isso, trataremos da relação performance e presença para pensar numa dinâmica de copresença nos meios digitais e trataremos os corpos analisados como corpos performáticos diante do que versam os autores de referência no campo.

A performance enquanto uma expressão cênica em função do espaço e do tempo é percebida como linguagem de experimentação, uma arte de intervenção que busca impactar os receptores através da apresentação de algo por um artista performer que esteja carregado de significado, estruturando-se assim "numa linguagem "cênicoteatral”, uma forma mixed-media (COHEN, 2002).

Ocorrendo em diversas instâncias e com tipos diferentes, a performance deve ser interpretada dentro do amplo espectro de ações humanas que inclui rituais e eventos da vida cotidiana, orienta Schechner (2013), salientando que os estudos de performance questionam-se sobre as circunstâncias nas quais a performance foi criada ou exibida - como, quando e por quem, como interagem com os que a veem e como ela muda ao longo do tempo. Para o autor, o performativo ocorre em lugares e situações que não são tradicionalmente marcados como artes performáticas. "Performances - de arte, rituais ou vida cotidiana - são comportamentos restaurados, comportamentos 
duplamente comportados, ações realizadas para as quais as pessoas treinam e ensaiam" (SCHECHNER, 2013, p.28, tradução das autoras)4.

Zumthor (2016) entende a performance como um acontecimento oral e gestual para o qual é impossível dar uma definição simples que relaciona às condições de expressão e percepção, "performance designa um ato de comunicação como tal; referese a um momento tomado como presente” (ZUMTHOR, 2016, p.50). Nesta lógica, a performance liga-se ao corpo e também ao espaço através de manifestações físicas obrigatórias; através do corpo, conectamo-nos à experiência dos textos e entendemos a materialização do que nos é próprio, da nossa realidade vivida (ZUMTHOR, 2016). Assim, a performance conecta-se à natureza do que é conhecido pelo meu corpo e, por isso, o modifica e o marca enquanto meio de comunicação, ou seja, a percepção suscita presença.

Cohen (2002) endossa a presunção da presença, o aspecto "ao vivo", e, portanto, um vídeo ou sua exibição não caracterizariam uma performance a menos que contextualizado e concomitante a uma atuação ao vivo. Desta forma, os vídeos que desejamos observar neste trabalho não constituiriam performance, por definição. No entanto, as características que o autor fornece para esta linguagem artística são verificáveis no nosso objeto de análise - há uma linguagem cênico-teatral que busca impactar os receptores através de processos de experimentação.

O que se destaca como constante nos conceitos de performance citados é a centralidade do corpo como aspecto categórico; o corpo é o meio que proporciona as experiências de contato com outrem sejam estas experiências presenciais, ou pela copresença no meio virtual. Apoiamo-nos na concepção de McLuhan (1969) dos meios de comunicação como extensões do homem ao tratarmos os objetos tecnológicos enquanto recursos que ampliam nossa percepção do mundo pelos sentidos e ainda pela simulação da presença. Enquanto extensões dos nossos sentidos, os meios implicam ainda em novos índices relacionais e entre si - o autor exemplifica como o rádio alterou as estórias noticiosas e a televisão interferiu na programação do rádio. Consequentemente, entendemos que as plataformas digitais de socialização também alteram índices relacionais dos indivíduos - pela simulação da presença dos que se

4 No original: "Performances mark identities, bend time, reshape and adorn the body, and tell stories. Performances - of art, rituals, or ordinary life - are "restored behaviors," "twice-behaved behaviors," performed actions that people train for and rehearse" (SCHECHNER, 2013, p.28). 
conectam pelas telas e pela extensão dos sentidos dos que se ouvem e veem através dos vídeos produzidos e publicados nas plataformas.

Assim, observaremos os corpos que atuam nos vídeos que, mesmo intermediados pelas telas e pela plataforma digital, são corpos reais que performam em um espaço e tempo real, portanto entendemos as mulheres que produzem os vídeos como performers que atuam numa copresença utilizando-se da oralidade pela fala ou pela musicalidade e gestualidade para comunicarem-se com os seus interlocutores. Schechner (2013) explica que comportamentos, ações, eventos ou coisas podem ser estudados como performance - o que significa na perspectiva de, em termos de. Um dos significados de performar é fazer as coisas de acordo com um cenário ou plano específico (SCHECHNER, 2013).

Pela analogia da vida social com o jogo e com o teatro, Goffman (1985) define a representação do eu na vida cotidiana como uma representação teatral que aciona diversos aspectos. $\mathrm{O}$ autor utiliza representação para referir-se às atividades de um indivíduo em um período caracterizado por sua presença diante de um grupo particular de observadores sobre os quais teria certa influência - a situação na qual nos colocamos define a forma como nos comportamos a depender das impressões que desejamos suscitar naqueles com quem temos contato. Desta forma, o mundo é reconhecido como um imenso palco em que somos atores representando papeis diversos em práticas interacionais visando uma influência recíproca e, mais uma vez, na presença física imediata (GOFFMAN, 1985). Situamos este grande palco no contexto digital e espetacular, uma vez que o campo das experiências é modulado pela interação com os outros e com o mundo, através de pressões histórico-culturais dentro dessas novas possibilidades (SIBILIA, 2008).

$\mathrm{Na}$ ambiguidade entre o artista e o personagem que representa, o ator ou a atriz se polariza e se mascara deste personagem, compondo algo, trabalhando uma máscara ritual distinta da sua persona cotidiana e são, assim, relatores de seu tempo, que captam e transmitem o que os outros estão sentindo (COHEN, 2002).

Para observar a parte dos indivíduos que performam regularmente para os que observam sua representação, Goffman (1985) delineia a ideia de fachada como equipamento expressivo empregado durante a representação; quando fala em fachada pessoal, incluem-se distintivos de função ou categoria social, vestimenta, gênero, idade, estatura - aparência em geral; atitude e padrões de linguagem, expressões 
faciais e gestualidade corporal; alguns destes elementos são fixos e não variam conforme a situação, enquanto outros são transitórios ou móveis. "Quando um ator assume um papel social estabelecido, geralmente verifica que uma determinada fachada já foi estabelecida para esse papel” (GOFFMAN, 1985, p.34). Assim, seja o papel que motivou a tarefa ou o desejo de manter a fachada, a tarefa deve ser cumprida pelo ator. Cidreira (2013) destaca o fenômeno recorrente na atualidade da exibição corporal dos indivíduos em seu dia a dia, em um processo de elaboração de autoimagem que só é possível, segundo a autora, a partir do reconhecimento de que a vivência pessoal depende de uma atuação corporal, que associa aspectos comportamentais e a própria aparência.

No nosso corpus de análise, percebemos que as quatro mulheres construíram no seu espaço digital um estilo de conteúdo pelo qual se tornaram reconhecidas e, consequentemente, enquanto atrizes-performers de si mesmas, espera-se que elas permaneçam desempenhando este tipo de papel para aqueles que as acompanham através das redes sociais. O corpo performativo (CIDREIRA, 2013) implica numa performatividade pura que acolhe o indivíduo no seu dia a dia, na cena cotidiana. Nesta, o ator se mostra através de seu corpo.

O entendimento de que o corpo é o meio pelo qual engajamo-nos com as coisas ampara-se na fenomenologia da percepção conforme Merleau-Ponty (1999) e nos orienta a pensar a relação entre os nossos corpos, como compreendemos e percebemos o outro. O corpo transcende a relação biológica e, nos parâmetros sociais, nos permite experimentar e perceber o mundo, sendo a experiência sensível um processo vital para as nossas relações com o outro. O mundo fenomenológico pressupõe uma intersecção de experiências próprias e experiências alheias, formadas por uma intersubjetividade (MERLEAU-PONTY, 1999). Por esta lógica, podemos assumir que, pelos processos comunicativos que engajam as influenciadoras digitais analisadas neste trabalho, a dinâmica que seus corpos executam pode influenciar e impactar aqueles que as acompanham pelos meios digitais, mas, mais importante ainda, impacta e afeta a elas mesmas enquanto corpos performáticos. Assim, a existência de uma performatividade relativa à vida cotidiana que se liga diretamente à expressão e percepção da cotidianidade nos dá responsabilidade pelas tramas que fluem através dos corpos e permitem fundir-se com os mesmos (CIDREIRA, 2013). 
Neste universo digital, a corporeidade das mesmas ocupa uma copresença pela qual podemos verificar uma situação performática. A dinâmica da teatralidade, a representação de si mesmas, a encenação e a fachada assumidas por estas são algumas das características que relacionam suas práticas com a ideia de performance e nos colocam diante do que chamamos de corpos performáticos. O corpo performático é invadido pela gestualidade, dinâmica e significados da performance, e é capaz de impactar e sensibilizar aqueles com os quais têm contato (mesmo que numa forma não ao vivo e não presencial) pela copresença viabilizada nos meios digitais.

\section{Narrativa audiovisual como elemento vinculador}

Considera-se narrativa uma cadeia de eventos que são conectados por causa e efeito, ocorrendo em determinados espaço e tempo, na linguagem cinematográfica (BORDWELL; THOMPSON; 2013), com características específicas como personagens e ação que os envolvam, eventos relacionados entre si e problemas ou conflitos que gerem alguma conclusão. As narrativas são fundamentais para compreendermos o mundo e entenderemos por narrativa as histórias que contamos, não necessariamente vinculadas a um formato rígido, mas capazes de criar vínculos entre identidades e diferenças em termos cognitivos e afetivos (MARTINO, 2016). Sentidos compartilhados com outras pessoas são transversais ao ato de contar uma história, que são um dos fatores mais relevantes para formar conexões entre pessoas, comunidades e sociedades (GERBNER apud MARTINO, 2016). É, portanto, um momento de encontro com o outro.

Martino (2016) aponta algumas vertentes de pensamento sobre a narrativa que discutem narrativas vinculadas a um formato ou meio, mas se interessa pela "narrativa como um dos componentes centrais do ato de comunicação, a partir da qual é possível uma compreensão específica desse fenômeno" (MARTINO, 2016, p.44). A ideia de comunicar advém da lógica do tornar comum e a narrativa se situa dentro desta lógica quando algo é efetivamente compartilhado com o outro, em um vínculo comunicacional, argumenta o autor. $\mathrm{O}$ ato narrativo diferencia-se dos outros atos comunicacionais pela forma - elabora-se um conjunto de enunciados a respeito de fenômenos não presentes no momento buscando uma perspectiva de compreensão entre duas ou mais pessoas que visam entender as implicações desses elementos. Ultrapassando a lógica de emissores e receptores, entende-se que falantes e ouvintes 
partilham um ambiente narrativo em posições diversas visando o compartilhamento de um sentido.

Sibilia (2008) sugere ainda que determinados usos confessionais da internet para expressar e partilhar a experiência de si poderiam ser manifestações dos velhos gêneros autobiográficos nos quais o eu que fala é autor, narrador e personagem que dialoga com as multidões virtuais, e este relato, assim como o personagem, "não representa simplesmente a história que se tem vivido: ele a apresenta. E, de alguma maneira, também a realiza, concede-lhe consistência e sentido, delineia seus contornos e a constitui" (SIBILIA, 2008, p.32).

A narrativa se configura também como nossa fonte comum de conhecimento da realidade - o que sabemos do mundo vem do que nos é contado e do que experimentamos; o que nos é contado possui marcas de contextos específicos e aspectos cognitivos daqueles que os narram. Estas condições formam o modo como entendemos o mundo e a forma como vou contá-lo para os outros e, portanto, o ato de classificar a realidade é um dos elementos fundamentais da narrativa (MARTINO, 2016). Para narrar o outro, preciso entendê-lo - um entendimento que depende de categorias minhas, numa recodificação do mundo. É a partir dessa apreensão prévia da realidade que se formam as narrativas, que se tornam parte do que entendemos por "realidade" (MARTINO, 2016).

Esta ideia de narrativa e classificação da alteridade auxilia a elaboração do conceito de estereótipo (LIPPMANN, 1976, apud MARTINO, 2016), que permite uma compreensão mais rápida da situação ou de uma pessoa, posto que a alteridade passa a ser entendida como um exagero de traços e apagamento de outros, numa apreensão unilateral que não permite compreender o outro em sua complexidade.

Sobre essa relação de alteridade com a narrativa, acrescentamos a ideia de sujeitos em comunicação discutida por França (2006), que descreve as narrativas como práticas capazes de ordenar sentidos e que são desenvolvidas por sujeitos nos processos comunicativos. Portanto, colocam-se em cena estes sujeitos em comunicação pela narrativa. A autora entende o sujeito em comunicação como sujeito social que está enredado numa teia de relações que o constituem enquanto interlocutores que falam com o outro e são unidos pelos laços discursivos que os unem (FRANÇA, 2006). A ação que constitui os sujeitos da comunicação é mais do que produção e recepção de discursos, mas a ação de afetar e ser afetado para e em 
decorrência do outro (FRANÇA, 2006). Quando um texto ou produto comunicacional (na nossa análise, vídeos na rede social) é publicado, os sujeitos que o apreendem são convocados e o respondem dentro de um sistema de agenciamento trazendo suas referências e experiências anteriores que são atualizadas naquela circunstância.

Ao produzirem vídeos para o reels do Instagram que versam sobre determinadas temáticas em fluxo, as influenciadoras digitais que analisamos se evidenciam como sujeitos em comunicação, que se utilizam deste meio para veicular narrativas de si; estas narrativas são marcadas pelos contextos individuais nos quais cada uma delas se colocou em sua trajetória virtual, que descreveremos a seguir.

Atentamos para a dimensão estética e afetiva da narrativa segundo Martino (2016), que entende o ato narrativo como parte de uma estética da comunicação - além de a apreensão ser um fato cognitivo, é um desafio à sensibilidade, pois acionamos categorias cognitivas e sensíveis ao vivenciar o contato com o outro; o ato de narrar e a narrativa do outro "torna-se uma possibilidade de experimentar, no espaço dos afetos, o que são as vivências do outro” (MARTINO, 2016, p.46), existindo como instrumento de vinculação, pois quando se compartilha uma história, permite-se estabelecer uma relação reflexiva entre os participantes - os que falam e os que se dispõem a ouvir.

Feitas tais considerações sobre o entendimento de narrativa, pensamos neste trabalho o conceito de audiovisual junto à origem do termo - imagem e som convergem para um mesmo meio (RIBEIRO, 2008); técnica concebida em um produto ou obra em um determinado meio de comunicação de massa que permite transmissão de som e imagem (JOURNOT, 2005, apud RIBEIRO, 2008). Para falar de narrativas audiovisuais, a produção de sentido deve advir dos componentes imagem, som e discurso que cumpram seu objetivo primordial de transmitir de modo eficaz determinada mensagem aos seus espectadores conforme Ribeiro (2008).

A matriz da linguagem audiovisual é o cinema, que durante anos criou e difundiu imagens e pensamentos sobre o mundo, sobre a humanidade, a sociedade, estimulando o refletir sobre as práticas sociais. Entendemos o recurso reels do Instagram como meio para narrativa audiovisual, pois através deste é possível criar e editar vídeos, utilizando imagem e som próprios (registrados pelo próprio criador) ou a partir do que foi salvo do banco de dados da ferramenta. As redes sociais como meio de comunicação de massa ganham através deste estilo de vídeo produzido uma 
possibilidade diferente de difusão e disseminação de imagens sobre o mundo, imagens que afetam e são capazes de estimular reflexões sociais.

Em seu trabalho, Ribeiro (2008) versa sobre a narrativa publicitária, comparando-a com a narrativa cinematográfica, e aponta características que nos interessam acionar para falar sobre as narrativas audiovisuais no Instagram. Segundo a autora, a narrativa audiovisual se constitui de elementos significantes que produzem determinados efeitos de sentido que só se efetivam quando são lidas pelos espectadores em um processo individual no qual o leitor-espectador aciona seus mecanismos de representação.

Dentre as aproximações teóricas concebidas neste trabalho, compreendemos que cinema e publicidade possuem técnicas e finalidades distintas entre si e ainda do objeto de análise da pesquisa, mas se assemelham enquanto formas narrativas e, portanto, tornam-se relevantes. Ao refletir sobre diversas técnicas de criação como a escrita e a fotografia, Sibilia (2008) observa que tanto as imagens como o texto (e nas outras linguagens que utilizamos como referências - o cinema e a publicidade) "não só testemunham, mas também organizam e inclusive concedem realidade à própria experiência. Essas narrativas tecem a vida do eu e, de alguma maneira, a realizam" (SIBILIA, 2008, p.33). Assim, o que ocorre nos vídeos do reels seria um esquema de exteriorização da intimidade, do individual.

Nos vídeos que analisamos, a utilização de certos recursos e marcas de estilo são verificadas de modo recorrente enquanto características da narrativa. Existem vídeos com músicas que são coreografadas e dançadas seguindo tendências de produtores de conteúdo do Brasil e do mundo. Também existem vídeos que são encenações cotidianas com áudios replicados, entre outros que detalhamos a seguir ao analisarmos os mecanismos de representação de cada uma das influenciadoras digitais que constituem nosso corpus de análise.

\section{Trajetórias, performances e narrativas}

Como este trabalho se debruça sobre fenômenos culturais on-line e seus elementos, no estágio de pré-análise, estabelecemos contato com o objeto de pesquisa através da opção "seguir" no Instagram, buscando conhecer o texto e invadir-nos de impressões para prosseguir com a análise de conteúdo qualitativa, conforme Bardin (2002). O método não se interessa na descrição dos conteúdos, mas no que estes 
podem nos ensinar e funciona em um corpus reduzido de pesquisa (BARDIN, 2002). Pela análise de conteúdo, procuramos compreender o sentido da comunicação buscando outra significação. As informações sobre a trajetória das mulheres que constituem o corpus de análise deste trabalho foram levantadas na etapa da préanálise, na qual observamos reportagens jornalísticas que descrevessem ou narrassem a vida daquelas mulheres. A hipótese levantada inicialmente fora a de que, com maior visibilidade no reels do Instagram, outras formas corporais aparecem e ocupam-se de contar histórias sobre as pessoas que os produzem.

A constituição do corpus definiu-se pela regra de representatividade, buscando expressar diversidade entre trajetórias, corpos e narrativas que analisamos a seguir. Realizamos, então, uma análise temática considerando o tema como a unidade de significação e registro a ser observada nesta análise de conteúdo. Bardin (2002) explica que a análise temática implica em descobrir núcleos de sentido que compõem a comunicação e cuja presença pode significar para o objeto analítico escolhido. "O tema é geralmente utilizado como unidade de registro para estudar motivações de opiniões, de atitudes, de valores, de crenças, de tendências, etc." (BARDIN, 2002, p. 106), juntamente com as unidades de contexto que nos auxiliam na análise qualitativa para a elaboração de inferências sobre os acontecimentos e performances evidentes nos vídeos. Combinamos a unidade tema com o personagem para entender quem e em que ocasião, com que papel e atributos as corporeidades daquelas mulheres são encarnadas para narrativas audiovisuais na ferramenta reels do Instagram.

\section{Tia Má: maternidade e empoderamento feminino}

Maíra Azevedo é jornalista, baiana, soteropolitana, mãe de Aladê (12 anos) e Yanna Luiza (1 ano); e, nas redes sociais, é Tia Má (no Twitter e no Instagram, o nome de usuário é @tiamaoficial; no Facebook é @ dicasdatiama). Em 2014, ela recebeu o prêmio de jornalismo Abdias do Nascimento, pelo caderno Especial da Consciência Negra. Em 2020, publicou seu primeiro livro "Como se livrar de um relacionamento ordinário”. Desde 2016 participa como parceira no programa da TV Globo Encontro com Fátima Bernardes, comentando pautas como racismo e relacionamentos. Como atriz, já apresentou o show de stand-up "Tia Má com a Língua Solta", abordando empoderamento feminino, racismo e autoaceitação e, em 2021, estreou como atriz numa produção do serviço de streaming Netflix. Essas informações nos auxiliam a 
delinear o contexto próximo no qual Tia Má está situada enquanto produtora de conteúdo.

A partir da análise flutuante dos vídeos no reels de Tia Má5, constatamos algumas formas de aparição que acompanham determinados conteúdos comumente. O vídeo-selfie é uma constante desde o início da funcionalidade - ela fala diretamente para a câmera, dialogando com seu interlocutor, não seguindo um script aparentemente. Nesses vídeos, frequentemente, Tia Má fala para mulheres sobre relacionamentos e práticas em relacionamentos que podem ser saudáveis ou não. $\mathrm{O}$ rosto fica sempre muito próximo da câmera e não traz uma produção de maquiagem ou acessórios, denotando uma cotidianidade naquele diálogo próximo e afetivo - são conselhos e recomendações para se viver melhor.

A gestação e maternidade de um adolescente e de um bebê também perpassam os temas dialogados, mas ganham destaque nos vídeos-dança. Em uma série, ela publica "dancinha do banho" com Yanna Luiza e alguns momentos em que dança com o filho mais velho Aladê. Os vídeos em que dança sozinha - músicas de estilos musicais populares (axé, pagode, brega funk, forró) também são constantes e, normalmente, não seguem uma coreografia padronizada. Neles, Tia Má dança livre e espontaneamente. A ancestralidade e a religiosidade são demarcadas pelas canções e a liberdade de ser é pulsante no dançar livremente.

Há também campanhas publicitárias com anúncios atravessando as temáticas recorrentes - um cartão de crédito (independência financeira); aplicativos de compras de supermercado (praticidade na vida cotidiana para mulheres ocupadas); cosméticos para cabelos cacheados (para quem usa o cabelo natural); presentes de chá de fraldas (uma mãe de bebê entende bem do assunto) - e são gravadas em cenas do cotidiano tomar café da manhã, preparar uma receita, rotina de autocuidado.

Neste nível de análise, as temáticas de relacionamentos, empoderamento feminino e maternidade atravessam os vídeos de Tia Má nos quais a sua corporeidade é vetor expressivo destas dinâmicas e pelas quais a narrativa de si toma forma. Nas duas primeiras temáticas, o olhar assertivo e expressão facial, e o uso das mãos para se movimentar enquanto fala diretamente aos seus interlocutores demarcam a proximidade entre a falante e seus interlocutores. Nesses vídeos, o sotaque demonstra

5 Disponível em <https://www.instagram.com/tiamaoficial/reels/?hl=pt-br>. Acesso em 29 de out. 2021. 
claramente as origens da capital baiana e a linguagem denota uma assertividade. A maternidade aparece através de cenas próximas de uma vida real - dar banho, cuidar da casa, cozinhar, cuidar e brincar com os filhos. Tia Má veste-se de forma simples pijamas, shorts, tops são algumas peças comuns - e aparece sem uma maquiagem artística elaborada na maioria dos vídeos; o corpo de uma mulher negra, baiana, mãe de dois, uma mulher gorda, é um corpo que dança ao som dos ritmos regionais desvelando sua origem.

\section{Dona Dirce: liberdade de ser aos 73}

Dirce Ferreira é de Uberlândia, Minas Gerais, aposentada, tem 73 anos e é Dona Dirce que, em 2019, replicou poses e fotografias de um ensaio sensual produzido pela neta e algumas fotos de famosas também sensuais. Com as fotografias postadas no perfil do Instagram, a idosa foi reconhecida por "quebrar o tabu" do que se espera que mulheres façam após os 70 anos. É esse o contexto no qual a nossa personagem tornase uma figura pública. Desde então, ela mantém uma conta ativa no Instagram, concede entrevistas e participa de programas de televisão para falar sobre o seu estilo de vida. Numa entrevista para a revista Marie Claire, afirmou que a idade a trouxe liberdade para fazer o que quisesse despreocupada com a opinião alheia; e se colocou como referência, pois ela mostraria a capacidade do idoso em ser moderno, dançar, viajar e se incluir na internet ${ }^{6}$.

Os vídeos publicados no reels por Dona Dirce7 possuem alguns padrões recorrentes; alguns destes seguem as tendências do que está sendo produzido e replicado no Instagram, uma performance mimética comum a diversos produtores de conteúdo que atuam nesta rede social. No entanto, ao replicar essas tendências, o traço do estilo de Dona Dirce fica evidente pela leveza e não fixação aos padrões de coreografias e rigidez na execução de transições ou movimentos. Comumente, Dona Dirce performa livremente pelas músicas e áudios populares na plataforma, concedendo àqueles sons os seus movimentos e a sua mobilidade.

\footnotetext{
${ }^{6}$ Fonte: <https://revistamarieclaire.globo.com/Beleza/noticia/2020/o7/com-mais-de-100-milseguinetos-dirce-ferreira-diz-que-idade-lhe-trouxe-liberdade.html>. Acesso em: 29 de out. 2021. Ver COM (2020).

7 Disponível em <https://www.instagram.com/donadirceferreira/reels/?hl=pt-br>. Acesso em: 29 de out. 2021.
} 
A legenda do que está sendo dito ou um texto explicativo fazem parte da maioria dos vídeos publicados, que ainda incluem campanhas publicitárias de aplicativos bancários, marcas de cosméticos e de lingerie - vestimenta que Dona Dirce traja na maioria dos seus vídeos, variando com roupas de banho e moda fitness. Ressaltamos as roupas que Dona Dirce veste nos seus vídeos, pois muitos respondem às críticas etaristas que ela recebe por não se vestir como alguém da sua idade supostamente deveria se vestir, ou por não se portar da "maneira adequada". A liberdade de ser uma mulher idosa, que dança de lingerie ou de biquíni no quintal de casa, é uma temática transversal aos vídeos de Dona Dirce que, em poucas vezes, fala, verbaliza estas ideias aos seus "seguinetos". No entanto, através do seu corpo performático e da narrativa construída pelo discurso audiovisual complementado pelo elemento textual, as mensagens ficam evidentes para os que são alcançados por aquelas publicações.

O corpo de Dona Dirce se movimenta e dança de uma forma própria a um corpo de 73 anos. Sem autoexigência de execução idêntica ao dos influenciadores digitais que publicam vídeos de tendências, percebemos o corpo de uma mulher do interior de Minas Gerais, que se movimenta e revela a sua forma física sem recursos de edição gráfica para omitir marcas naturais do envelhecimento.

\section{Pequena Lô: humor inspirado pela vida}

A psicóloga Lorrane Silva começou a produzir vídeos para o YouTube falando sobre bullying e preconceitos, especificamente contra pessoas com deficiência em 2015. Lorrane possui uma síndrome rara nomeada pelos médicos como displasia óssea que faz com que ela tenha um encurtamento dos membros e da estatura. Para a sua mobilidade, utiliza muletas e, quando sai de casa, uma scooter a auxilia. O nome pelo qual se apresenta nas plataformas digitais é Pequena Lô. Em meados de 2020, alcançou milhões de pessoas produzindo vídeos de teor humorístico para a plataforma TikTok. Em algumas entrevistas, ela relata o labor para a produção dos vídeos nos quais encarna personagens - há um processo de produção de roteiro, ensaio, dublagem e atuação - e declara estar satisfeita em ser reconhecida como Pequena Lô, que faz vídeos divertidos, e não como a Pequena Lô, a menina com deficiência. A atuação e a existência de personagens colocam os vídeos de Pequena Lô numa perspectiva que a diferencia de Tia Má e Dona Dirce. Essas são as marcas contextuais dessa personagem que analisamos a seguir. 
Características diferentes dos perfis analisados anteriormente são conformadas nos vídeos da Pequena Lô ${ }^{8}$. A narrativa humorística engloba normalmente uma situação descrita por escrito ou através de fundos virtuais (recurso técnico do aplicativo), música ou áudio que orientam a atuação dela. Algumas situações são: diálogo entre mãe e filha, conversa entre duas amigas, na terapia com psicóloga e paciente, situações sobre relacionamentos. Em todas, Lorrane é atriz e demarca as personagens através de perucas e vestimentas simples que as diferencia. Em algumas delas, Lorrane performa os diálogos entre duas personagens falando. Em outras, a legenda e expressão corporal dão conta dos sentidos que se deseja atribuir àquele fragmento situacional.

Nas entrevistas e reportagens jornalísticas, Lorrane conta ser inspirada pelas situações que já viveu na época de faculdade e entre as amigas, a família; o relato destas experiências flui pelas personagens - Robertinha e Bruna - que interagem com a própria Lô. Pequena Lô também reproduz coreografias das tendências dos aplicativos de vídeo e produz campanhas publicitárias pelo mesmo estilo de narrativa.

A narrativa humorística de Pequena Lô utiliza-se da lógica teatral para dialogar com a sua audiência - quando não encena as personagens criadas, a personagem é ela mesma nas situações da vida cotidiana. Em uma das entrevistas consultadas, a psicóloga também afirma que o humor não foi um mecanismo para lidar com a deficiência, que não é a pauta central das produções, conforme percebemos ao analisarmos o conteúdo publicado no reels. O corpo de Lorrane performa na dissidência principalmente pela atuação - ela narra e incorpora personagens distintas demarcadas por recursos visuais como figurino, perucas e maquiagem, além dos aspectos técnicos que a plataforma permite -, não omitindo as muletas ou a scooter que a acompanha para auxiliar no deslocamento e na mobilidade.

\section{Alexandra Gurgel: corpo livre e representatividade}

Alexandra Gurgel é jornalista e deu início em 2015 ao canal no YouTube “Alexandrismos”, no qual iniciou a discussão sobre autoaceitação através de relatos da própria experiência enquanto uma mulher gorda. Submeteu-se a dietas desde muito cedo, viveu transtornos alimentares e, aos 23 anos, fez uma cirurgia plástica, cujos

8 Disponível em: https://www.instagram.com/_pequenalo/reels/?hl=pt-br. Acesso em: 29 de out. 2021. 
resultados afetaram a forma como ela se percebia e apreendia o mundo. O livro "Pare de se odiar" foi lançado em 2018 e, em 2021, Gurgel lançou "Comece a se amar”. A fundadora do Movimento Corpo Livre no Brasil questiona padrões estéticos sobre os corpos femininos, pauta a gordofobia e a aceitação de todos os corpos com postagens constantes no perfil pessoal no Instagram e em seu canal no YouTube, que ficou sem atualizações por algum tempo, retornando à ativa em julho de 2021. Neste contexto que se situa nossa personagem de análise.

A jornalista aparece em seus vídeos no reels ${ }^{9}$ majoritariamente trajando biquínis - a peça de roupa que é constantemente evitada ou sequer utilizada por mulheres gordas. O uso de biquínis é, inclusive, abordado buscando naturalizar a exposição do seu próprio corpo, uma possível consequência da aceitação das suas formas.

Destacamos os vídeos em que Alexandra aconselha ou interpela seus interlocutores sobre a jornada de autoaceitação, amor próprio, autoestima, autoconfiança - sempre acompanhados da frase “Bora um dia de cada vez?”. Além desses, há vídeos de caráter informativo nos quais Alexandra comenta notícias relacionadas à representatividade de pessoas gordas nos meios midiáticos, procedimentos estéticos, episódios de body shaming ${ }^{10}$ com celebridades, entre outros eventos noticiosos relacionados à corporeidade e aparência. A audiodescrição é uma constante em vídeos nos quais Alexandra fala para o seu público.

Algumas personagens aparecem em seus vídeos nos contextos da "Clínica Sempre Magra”, "Clínica Gorda Nunca mais", “Any Any Coach de Beleza” e "Mãe e filha”; a demarcação das personagens através da vestimenta, maquiagem e perucas é comum e os diálogos centram-se em temas como filtros do Instagram, harmonização facial, emagrecimento imediato e alimentação saudável. A atuação ironiza a forma como a indústria da beleza explora a insegurança das mulheres e a maneira como as pessoas interpelam pessoas gordas em sua cotidianidade.

Assim como Tia Má, Dona Dirce e Pequena Lô, Alexandra performa as danças e coreografias das tendências do Instagram e faz vídeos com caráter publicitário dentro

\footnotetext{
9 Disponível em: https://www.instagram.com/alexandrismos/reels/?hl=pt-br. Acesso em: 29 out. 2021.

${ }^{10} \mathrm{O}$ termo body shaming define o comportamento de ridicularizar ou criticar a aparência física de uma pessoa. Fonte: https://vogue.globo.com/Vogue-Gente/noticia/2019/10/o-peso-do-body-shaming-osignificado-e-nuances-da-pressao-estetica.html. Acesso em: 29 out. 2021. Ver FERRAZ (2020).
} 
do estilo de conteúdo que produz para o Instagram. Além da própria Alexandra Gurgel, outros corpos aparecem e performam junto a ela - outros influenciadores digitais e sua esposa, a publicitária Carol Caixeta, fomentando, assim, não só a visibilidade de corpos gordos, mas acionando ainda a visibilidade LGBTQIA+.

A narrativa audiovisual no reels de Alexandra Gurgel reúne aspectos comuns às outras três personagens examinadas neste trabalho. Assim como Tia Má, Alexandra dança livremente as músicas do funk, evocando a origem carioca, e ocupa os espaços domésticos para registrar essas pequenas performances de dança (prática que Dona Dirce também executa). Da mesma maneira que Dona Dirce expõe as suas formas corporais, não obstante da sua forma de um corpo idoso, Alexandra expõe o corpo gordo livre e interpela seus interlocutores verbalmente para a liberdade de serem e aparecerem nas redes como desejam. A atuação e encenação de situações que permeiam sua vida são comuns à Pequena Lô e Alexandra, que utilizam o humor e a ironia como recursos narrativos ao interpelar os seguidores-espectadores.

\section{Considerações finais}

Ao observarmos especificamente a funcionalidade reels do Instagram, percebemos potencialidade para narrativas audiovisuais dos indivíduos que utilizam esse recurso que está disponível para todos os usuários - não somente para influenciadores digitais ou produtores de conteúdo. Ao filmar, dançar, editar, falar e legendar os vídeos, cada usuário performa uma narrativa de si que afeta aqueles que têm acesso aos vídeos - sejam seguidores ou não do perfil que o publica. Tais narrativas ganham forma através da corporeidade, uma vez que o rosto, o corpo, a gestualidade e a vestimenta são fundamentais na composição dos vídeos que são produzidos, além dos cenários virtuais ou reais.

A partir da análise dos vídeos publicados entre agosto de 2020, quando estreou a funcionalidade, e outubro de 2021, propomos algumas inferências a respeito das personalidades no nosso corpus de análise. Os índices temáticos são fundamentais numa análise qualitativa (BARDIN, 2002) e, para além das tendências de coreografias miméticas que são comuns neste tipo de plataforma e das personagens criadas por algumas delas, verificamos três dimensões que foram transversais à Tia Má, Dona Dirce, Pequena Lô e Alexandra Gurgel na lógica de narrativa audiovisual através dos corpos performáticos. Primeiramente, percebemos os corpos pelas suas formas 
diversificadas - corpo negro, gordo, idoso, deficiente - e enquanto corpos que dançam e atuam com movimentos significativos sobre quem são. Tia Má é uma mulher baiana, negra e mãe de dois, que dança ao som do pagode e axé baiano. Dona Dirce dança os mais diversos estilos musicais com os seus trejeitos próprios de um corpo de 73 anos. Alexandra Gurgel e Pequena Lô encenam situações que teriam vivenciado e também dançam diante das câmeras, desvelando um corpo gordo e um corpo de uma pessoa com deficiência.

Em seguida, observamos a utilização da linguagem oral, através da fala, e escrita, com a audiodescrição ou legenda, para que estes corpos não somente se comuniquem pela gestualidade, mas também interpelem seus espectadores nas pautas assertivas sobre o empoderamento feminino e relacionamentos nos reels de Tia Má, por meio do viés humorístico de Pequena Lô, dos comentários das notícias, da militância pelo corpo livre de Alexandra Gurgel, e das respostas aos comentários etaristas no perfil de Dona Dirce.

Por último, inferimos sobre o corpo como capital, uma nuance que se revela distinta do que já fora estudado por Pinto (2019), observando corpos canônicos de influenciadoras digitais no universo de magreza e fitness. Goldenberg (2010 apud PINTO, 2019) argumenta que o corpo jovem, magro, em boa forma, é um capital capaz de tornar superior quem o possui. Esse aspecto é verificado através do recurso publicitário em ambos os contextos - nos corpos cânones analisados por Pinto (2019) e, também, nos que observamos neste trabalho: corpos dissidentes que também centralizam narrativas publicitárias dentro das personagens que são incorporadas.

Deste modo, o corpo performático nas redes sociais responde a uma necessidade da vida social pandêmica que encontrou neste espaço um lugar para representação e relatos da cotidianidade. Analisando as publicações das influenciadoras digitais Tia Má, Dona Dirce, Pequena Lô e Alexandra Gurgel, verificamos que há um relato expressivo que flui através dos corpos que dançam, que gesticulam, que atuam, que falam e carregam significados vinculadores entre aquelas que produzem e os que são atingidos e afetados por estas performances virtuais. Em um contexto pós-pandemia, esses tipos de expressão que ganharam projeção durante a pandemia devem ter continuidade pela facilidade de acesso a este recurso, que é acessível a muitas pessoas.

Os recursos performáticos utilizados por estas perpassam a linguagem oral e escrita; a gestualidade com a dança, as mãos, o olhar; e a demarcação das narrativas 
também pela vestimenta. Essa forma dos corpos serem visibilizados e das narrativas de si via plataformas digitais devem continuar reverberando nas práticas comunicacionais.

Salientamos ainda que essas performances constituem dinâmicas narrativas pelas quais as influenciadoras digitais partilham sentidos com os seus interlocutores. O conjunto de características que verificamos nas narrativas audiovisuais destes corpos performáticos aponta para uma dinâmica comunicacional mais fluida nos relatos do cotidiano pelas redes sociais; esses relatos foram observados neste trabalho nos corpos de influenciadoras digitais considerando as trajetórias públicas das mulheres que analisamos. Entendemos que essa potencialidade intensificada na pandemia permanecerá como uma via para a visibilidade e a exposição das múltiplas corporeidades através das redes sociais.

\section{Referências}

APRESENTAMOS o recurso Reels do Instagram, Blog do Instagram. São Paulo, 5 ago. 2020. Disponível em <https://about.instagram.com/pt-

$\mathrm{br} / \mathrm{blog} /$ announcements/introducing-instagram-reels-announcement $>$. Acesso em 3 jan. 2022.

BARDIN, Laurence. Análise de conteúdo. Lisboa: Edições 70, 2002.

BORDWELL, David; THOMPSON, Kristin. A arte do cinema: uma introdução. Campinas: Editora da Unicamp, São Paulo: Editora da USP, 2013.

COHEN, Renato. Performance como linguagem. São Paulo: Perspectiva, 2002.

COM mais de 100 mil 'seguinetos', Dirce Ferreira diz que a idade lhe trouxe liberdade. Marie Claire, São Paulo, 26 de jul. 2020. Disponível em < https://revistamarieclaire.globo.com/Beleza/noticia/2020/07/com-mais-de-100mil-seguinetos-dirce-ferreira-diz-que-idade-lhe-trouxe-liberdade.html > . Acesso em 3 dez. de 2022.

CIDREIRA, Renata Pitombo. As formas da moda: comportamento, estilo e artisticidade. São Paulo: Annablume, 2013.

FERRAZ, Ju. O peso do body shaming: o significado (e as nuances) da pressão estética. Vogue, São Paulo, 29 de out. de 2021. Disponível em <https://vogue.globo.com/Vogue-Gente/noticia/2019/10/o-peso-do-body-shamingo-significado-e-nuances-da-pressao-estetica.html>. Acesso em 3 dez. 2022. 
FRANÇA, Vera. Sujeito da comunicação, sujeitos em comunicação. In: GUIMARÃES, C.; FRANÇA, V. R. V. (Org.). Na mídia, na rua: narrativas do cotidiano. Belo Horizonte: Autêntica, 2006, p.61-88.

GOFFMAN, Erving. A representação do eu na vida cotidiana. Petrópolis: Vozes, 1985 .

MARTINO, Luís Mauro Sá. De um eu ao outro: narrativa, identidade e comunicação com a alteridade. Parágrafo, v. 4, n. 1, p. 40-49. jan./jul. 2016.

MCLUHAN, Marshall. Os meios de comunicação como extensões do homem. São Paulo: Editora Cultrix Ltda., 1969.

MERLEAU-PONTY, Maurice. Fenomenologia da percepção. São Paulo: Martins Fonte, 1999.

PINTO, Naiara Moura. O corpo feminino na mídia: um olhar sobre a revista Boa Forma e as influenciadoras digitais do Instagram. 2019. Dissertação (Mestrado em Comunicação) -Programa de Pós-Graduação em Comunicação, Universidade Federal do Recôncavo da Bahia, Cachoeira, 2019. Disponível em < https://www.ufrb.edu.br/ppgcom/images/NAIARA PINTO dissertac a o versa 0 impress\%C3\%A30.pdf > Acesso em: 10 dez. 2021.

RECUERO, Raquel. Redes Sociais na Internet. Porto Alegre: Sulina, 2014.

RIBEIRO, Ana Margarida. A Narrativa Audiovisual: O Cinema e o Filme Publicitário. 2021 Dissertação (Mestrado em Ciências da Comunicação) - Instituto de Ciências Sociais, Universidade do Minho. Minho, Portugal, 2008. Disponível em: http://repositorium.sdum.uminho.pt/handle/1822/9476. Acesso em: 21 out. 2021.

SCHECHNER, Richard. Performance Studies: An Introduction. New York, Ed. Routledge, 2013.

SIBILIA, Paula. O show do eu: A intimidade como espetáculo. Rio de Janeiro: Nova Fronteira, 2008.

ZUMTHOR, Paul. Performance, recepção, leitura. São Paulo: Cosac Naify, 2016.

Este é um ARTIGO publicado em acesso aberto (Open Access) sob a licença Creative Commons Attribution, que permite uso, distribuição e reprodução em qualquer meio, sem restrições, desde que o trabalho original seja corretamente citado. 